\title{
Effect of Fetal Movements and Fetal Breathing on Fetal Middle Cerebral Artery Pulsatility Index Measurement
}

\author{
Anirudh Badade1, K. Khatal', Amar Bhide² \\ ${ }^{1}$ Chikitsa Diagnostic and Ultrasound Training Centre, Mumbai, India \\ ${ }^{2}$ Fetal Medicine Unit, St. George's Hospital, London \\ Email: chikitsa1995@yahoo.co.in
}

How to cite this paper: Badade, A., Khatal, K. and Bhide, A. (2018) Effect of Fetal Movements and Fetal Breathing on Fetal Middle Cerebral Artery Pulsatility Index Measurement. Open Journal of Obstetrics and Gynecology, 8, 354-361.

https://doi.org/10.4236/ojog.2018.84039

Received: June 23, 2017

Accepted: April 13, 2018

Published: April 16, 2018

Copyright $\odot 2018$ by authors and Scientific Research Publishing Inc. This work is licensed under the Creative Commons Attribution International License (CC BY 4.0).

http://creativecommons.org/licenses/by/4.0/

\begin{abstract}
Objective: This study aimed to determine the effect of fetal movements on the MCA pulsatility index (PI) and quantify the fall of MCA PI after initiation of fetal movements and/or breathing, and the time taken to recover from a fall below the $5^{\text {th }}$ percentile. Methods: 16 women with appropriate for gestational age (AGA) fetuses and 16 women with small for gestational age (SGA) fetuses were recruited. MCA PI during "no movement" state was compared with MCA PI values during fetal body movements and breathing movements. Results: MCA PI measurements with body or breathing movements were significantly $(p<0.005)$ lower as compared to that observed without movements. MCA PI started rising immediately after cessation of body movements and/or breathing movements. Conclusions: MCA PI with fetal body or breathing movements is significantly lower as compared to that observed in the quiet state. If MCA PI measurement is below $5^{\text {th }}$ centile, it should be measured again up to 90 seconds after cessation of fetal body and/or breathing movements in order to minimize false positive diagnosis of cerebral sparing effect in SGA as well as AGA fetuses.
\end{abstract}

\section{Keywords}

Variation of Fetal MCA PI, Fetal MCA Doppler, Fetal Movements, Fetal Breathing, Antenatal Doppler, Cerebral Sparing Effect

\section{Introduction}

Middle cerebral arterial (MCA) Doppler is an important investigation in the assessment of fetal oxygenation status [1]. Fetal hypoxia causes cerebral vasodila- 
tation which can be detected by Doppler as low MCA pulsatility index (PI) values [2]. MCA PI nomograms are available and values below the $5^{\text {th }}$ centile are interpreted as representing hypoxia-induced cerebral-sparing effect [3]. MCA PI values are used for timing delivery of hypoxic fetuses especially after time of fetal maturity [4] [5]. Therefore, it is important to measure the MCA PI accurately.

In the context of a small for gestational age (SGA) fetus, decreased MCA PI is associated with fetal hypoxemia [1]. Values below the $5^{\text {th }}$ centile are thought to represent fetal hypoxemia [6] [7]. It has been commonly observed that the MCA PI falls when the fetus is moving [8]. Also, several studies in literature have noted the variation of fetal Doppler indices with fetal behavioral states and fetal movement [9]. It is common practice, therefore, that fetal spectral Doppler readings should be taken when there is absence of fetal movements and fetal breathing [10]. We hypothesized that if the MCA PI fell below the $5^{\text {th }}$ centile in appropriate for gestational age (AGA) or small for gestational age fetuses due to fetal movements, it may have the potential to create a false positive diagnosis of cerebral sparing effect. A systematic search of published literature did not show any definite studies quantifying the degree of fall of MCA PI due to fetal movements.

Therefore, this study was conducted to determine the effect of fetal movements on MCA PI. The aim was to determine, how often and how quickly the MCA PI fell after initiation of fetal movements and/or breathing, how much it fell, how often it went below the $5^{\text {th }}$ centile, how much time it took to recover to a value above the $5^{\text {th }}$ centile, and how quickly it recovered after cessation of the fetal movements and/or breathing.

\section{Methods}

The study was approved by our institutional review board. Approval from ethics committee of our institution (Chikitsa: Centre for Excellence in Ultrasound), was obtained (No. INW/02/FEB/2015).

A total of 32 pregnant women with singleton fetus and no obvious structural abnormalities were included in this study. All women provided informed consent. Fetal weight reference ranges that fitted local population [11] were used to determine whether fetuses were appropriate or small for gestational age. SGA was defined as fetal weight below 10th centile. 16 women with AGA fetuses and 16 with SGA fetuses were recruited for the study. Crown-rump length obtained in the first trimester (10 - 14 weeks) was used to date all pregnancies. Women with SGA fetuses were recruited without regard for cerebral sparing effect. Cerebral sparing effect was said to be present if the MCA PI was below the $5^{\text {th }}$ centile even in absence of fetal body or breathing movements. Two examiners participated in the study, having sonography experience of 25 years and five years. A Philips HD 11 ultrasound scanner was used for the study. The reference ranges by Ebbing et al. [3] were used to determine the $5^{\text {th }}$ centile.

Prior to taking each MCA PI reading, the fetus was checked for presence or absence of any fetal body movement or breathing movement. The state of the 
fetus was classified as: "body movement present" or "breathing present" or "no movement". MCA waveforms were obtained as recommended [10] immediately thereafter. The mean MCA PI reading was taken as representing the multiple MCA PI readings during the corresponding fetal state. This cycle of checking for fetal movement/breathing followed by MCA PI measurement was repeated over and over continuously without any intervals. This cycle of checking for fetal movement/breathing followed by MCA PI measurement was repeated over and over continuously without any delays. Multiple serial readings of MCA PI were obtained for each fetus. The sample volume was placed on the proximal third of the MCA from its origin. Each examination was completed in a single sitting.

The MCA PI readings were obtained in any one waveform in a region of 3 uniform waveforms. Three to 15 waveforms were obtained for each reading. While measurement of MCA PI from waveforms obtained during fetal stages of "no movement" and "body movement present" was straightforward, the same during presence of fetal breathing required special consideration. An experienced Radiologist divided the waveforms obtained during fetal breathing into "visually uniform" waveforms (Figure 1(a) and Figure 1(b)) and "variable waveforms" (Figure 1). The "visually uniform" waveforms were obtained during quiet breathing and the "variable waveforms" were obtained during vigorous breathing. Whereas the MCA PI measurement in "visually uniform" waveforms was straightforward, the same in the "variable waveforms" was taken in any one waveform in a region of 3 uniform waveforms (Figure 2). We accepted this approximation because the "visually uniform" waveforms constituted $75.2 \%$ $(192 / 255)$ whereas the "variable waveforms" constituted $24.7 \%(63 / 255)$ of the waveforms obtained during fetal breathing.

\section{Statistical Analysis}

Ratio data were expressed as mean (standard deviation) or median (range). The percentage change in pulsatility index due to body or breathing movements was calculated for all subjects and quantified as median and range. The number of MCA PI readings which fell below the $5^{\text {th }}$ percentile during body movement and breathing movement were compared with number of MCA PI readings during no movement by chi-square test. Whenever MCA PI fell below $5^{\text {th }}$ centile, the average time taken for it to recover above $5^{\text {th }}$ centile was calculated (recovery time). The five SGA fetuses with cerebral sparing effect had MCA PI below the $5^{\text {th }}$ centile even in the "no movement" state and so were not included in the calculation of the "recovery time" of MCA PI. Mean MCA PI was calculated for each of the movement states for a fetus from the multiple measurements obtained. Repeated measures analysis of variance (ANOVA) was used to compare the MCA PI values from each fetus in the three states of no movements, body movements and breathing movements with SGA or AGA group as a factor. Bonferroni post-hoc test with correction for multiple testing was used to compare the three movement states. $p<0.05$ was considered as statistical significance. SPSS V20 was used for statistical tests. 


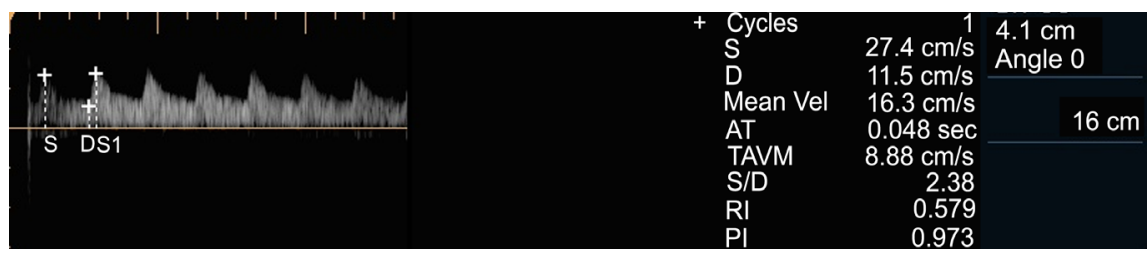

(a)

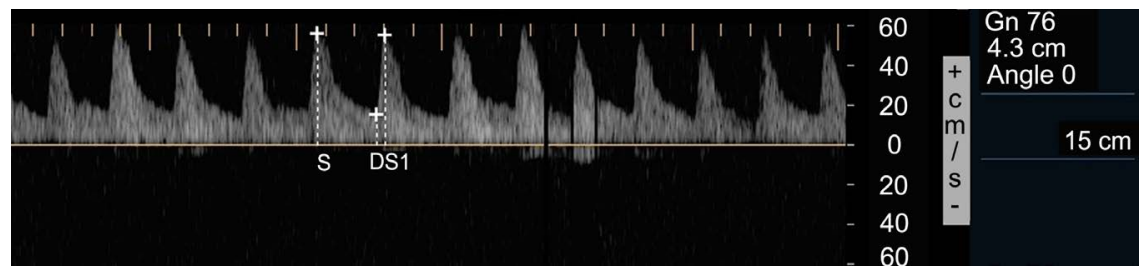

(b)

Figure 1. (a) \& (b) uniform waveforms noted during quite fetal breathing in 2 different AGA fetuses, posing no problem to measurement of the PI.

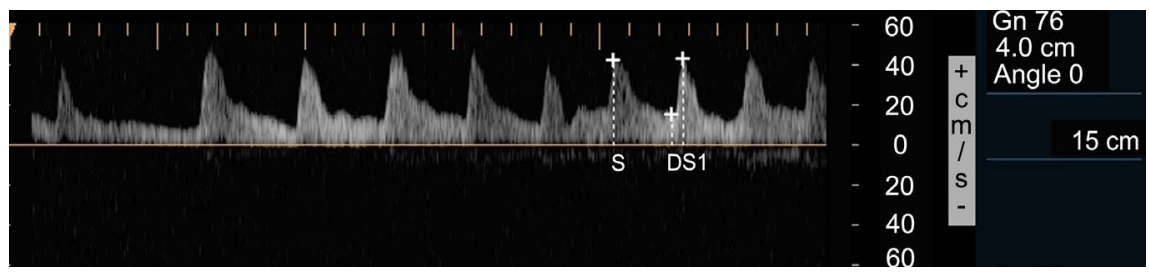

Figure 2. Variable waveforms noted during vigorous breathing in the same fetus depicted in figure 2. Measurement of the PI has been done in any one waveform in a region of 3 uniform waveforms.

\section{Results}

The baseline demographics of the participating women are shown in Table 1 . Women with SGA fetuses were significantly younger as compared to those with AGA fetuses. The gestational age at the ultrasound examination was no different. The mean duration of examination was no different in the two groups, but the mean number of readings obtained from the AGA group was higher as compared to SGA group. This difference was statistically significant. As expected, SGA foetuses were delivered significantly earlier and were significantly lighter as compared to the AGA group.

The details of the ultrasound assessment are shown in Table 2. In the state of quiescence, cerebral sparing effect was not seen in AGA fetuses, but was present in 5 out of the 16 SGA fetuses (31.25\%). In all fetuses, a fall in MCA PI was noted when fetal movements and/or breathing started after a period of no movements, and rise in the MCA PI was observed when the fetus achieved a state of quiescence. The fall in MCA PI was noted immediately when body or breathing movements occurred.

In order to quantify how often the MCA PI fell below the $5^{\text {th }}$ centile due to fetal movements or breathing, the number (percentage) of readings where the PI fell below $5^{\text {th }}$ percentile were compared.

An immediate rise in the MCA PI was noted when the fetus achieved a state 
Table 1. Baseline demographics of the study participants.

\begin{tabular}{cccc}
\hline Characteristic & AGA fetus & SGA fetus & Significance \\
\hline Mean maternal age in years (SD) & $28.7(4.2)$ & $23.5(2.5)$ & 0.018 \\
Gestational age at scan (Weeks) & $35.8(3.2)$ & $36.1(2.0)$ & 0.75 \\
Gestational age at delivery (Weeks) & $39.1(1.3)$ & $37.8(1.6)$ & $<0.005$ \\
Birth weight (g) & $3072(535)$ & $1943(328)$ & $<0.0005$ \\
Duration of study (min) & $14.6(3.3)$ & $13.7(5.0)$ & 0.57 \\
Number of recordings & $34(4)$ & $29(8.5)$ & 0.028 \\
\hline
\end{tabular}

Table 2. Details of the ultrasound and doppler examination. Results expressed as mean (SD), n (\%) or median (range).

\begin{tabular}{|c|c|c|c|}
\hline Ultrasound findings & AGA fetus & SGA fetus & $\begin{array}{c}p \text {-value } \\
\text { (Significance) }\end{array}$ \\
\hline Duration of study (min) & $14.6(3.3)$ & $13.7(5.0)$ & 0.57 \\
\hline Number of recordings & $34(4)$ & $29(8.5)$ & 0.028 \\
\hline MCA PI with no movements & $1.68(0.31)$ & $1.50(0.35)$ & \\
\hline MCA PI with body movements & $1.34(0.31)$ & $1.16(0.21)$ & $<0.005 \$$ \\
\hline MCA PI with breathing movements & $1.37(0.31)$ & $1.25(0.19)$ & \\
\hline $\begin{array}{c}\text { MCA PI }<5^{\text {th }} \text { centile without } \\
\text { movements }\end{array}$ & $0 / 235(0.0 \%)$ & $95 / 245(38.8 \%)$ & $<0.005$ \\
\hline $\begin{array}{c}\text { Number of readings with MCA } \\
\text { PI }<5 \text { th centile with body } \\
\text { movements }(\%)\end{array}$ & $32 / 64(50 \%)$ & $137 / 146(93.83 \%)$ & $<0.005$ \\
\hline $\begin{array}{c}\text { Number of readings with MCA } \\
\text { PI }<5 \text { th centile with breathing } \\
\text { movements }(\%)\end{array}$ & $66 / 88(75 \%)$ & $73 / 91(80.2 \%)$ & 0.402 \\
\hline $\begin{array}{c}\text { Median \% fall in MCA PI with body } \\
\text { movements (Range) }\end{array}$ & $\begin{array}{c}17.56 \% \\
(64.38 \% \text { to }-31.68 \%)\end{array}$ & $\begin{array}{c}10.99 \% \\
(56.29 \% \text { to }-66.18 \%)\end{array}$ & $0.001^{\star}$ \\
\hline $\begin{array}{l}\text { Median \% fall in MCA PI with } \\
\text { breathing movements (Range) }\end{array}$ & $\begin{array}{c}18.57 \% \\
(48.41 \% \text { to }-37.31 \%)\end{array}$ & $\begin{array}{c}6.76 \% \\
(45.67 \% \text { to }-103.39 \%)\end{array}$ & $<0.001^{*}$ \\
\hline $\begin{array}{l}\text { Median time to recovery after no } \\
\text { movements in seconds (Range) }\end{array}$ & 20 (12 to 169$)$ & 17 (12 to 105$)$ & $0.47^{\star}$ \\
\hline
\end{tabular}

\$ = Repeated measures ANOVA. Significant difference between no movements compared to both body and breathing movements $(p<0.005)$. No significant difference between body and breathing movements $(p=$ 0.094). * By Mann-Whitney U test.

quiescence. The time taken for MCA PI to recover from the drop in PI fallen below $5^{\text {th }}$ percentile (due to body movements or breathing/or both) to above the $5^{\text {th }}$ centile (due to cessation of movements/breathing) was calculated (recovery time). All fetuses in the AGA as well as the SGA category had episodes of MCA PI falling below the $5^{\text {th }}$ percentile. The median recovery time for AGA fetuses was 20 seconds (range: 12 - 169 seconds) and 17 seconds (12 - 105 seconds) for SGA fetuses. The percentage fall in MCA PI due to body and/or breathing movements was noted to be lower in the SGA fetuses compared to the AGA fetuses, possibly because the mean MCA PI was lower in the SGA fetuses. 


\section{Discussion}

Fetal breathing alters spectral waveforms in fetal blood vessels [12] [13]. It has been reported that physiological variables such as fetal movements affect the doppler hemodynamic waveforms and that fetal activity causes increase in cerebral vasodilatation and cerebral blood perfusion and that the opposite occurs during fetal quiescence [9]. Clerici et al. [8] in 2002 reported a statistically significant decrease of pulsatility index in the middle cerebral artery (MCA) during fetal "activity" and recommended that the fetal behavioral state should be considered while interpreting fetal waveforms.

An immediate drop in the MCA PI upon the onset of fetal activity (fetal body or breathing movements) was observed following a period of fetal inactivity. The mean MCA PI was highest in the fetal state of quiescence. MCA PI was lower with body or breathing movements. The median percentage fall in MCA PI due to onset of fetal movements was higher in the AGA fetuses (17.56\%, Range: (Fall of 64.38-Increase of 31.68\%)) than in the SGA fetuses (10.99\%\%, Range: Fall of 56.29-Increase of 66.18\%, $p=0.001$, Mann-Whitney U test). The median percentage fall in MCA PI due to onset of fetal breathing was higher in the AGA fetuses (18.57\%, Range: (Fall of 48.41-Increase of 37.31\%)) than in the SGA fetuses (6.76\%, Range: Fall of 45.67-Increase of 103.39\%, $p \leq 0.001$, Mann-Whitney $\mathrm{U}$ test). The most likely reason for this observation is that the MCA PI was already lower in SGA fetuses as a result of hypoxemia.

The drop as a result of onset of fetal movements and/or breathing caused MCA PI values to reach below the $5^{\text {th }}$ centile in $50 \%$ and $75 \%$ observations with body and breathing movements respectively in AGA fetuses. The corresponding figures for SGA fetuses without cerebral sparing effect were 93.8 and $80.2 \%$ respectively with body and breathing movements. The five SGA fetuses with cerebral sparing effect already had MCA PI values below $5^{\text {th }}$ centile in absence of fetal activity. The median time taken for MCA PI to recover to a value above the $5^{\text {th }}$ centile from the lowest reading in AGA fetuses was 20 (Range: 12 - 169) sec whereas it was 17 (Range: 12 - 105) sec for SGA fetuses without cerebral sparing effect ( $p=0.4721$, Mann-Whitney U test).

\section{Strengths and Limitations}

Some limitations should be acknowledged. A relatively small sample size is a limitation. However, multiple observations were obtained. The same fetus was studied at rest and with activity (body and breathing movements), increasing the power of the study. It is known that vigorous fetal breathing movements results in significant variability in measurement of PI and may impact the estimated comparison. However, the number of waveforms obtained for each reading ranged from 3 to 10 which would reduce the variability. All measurements were obtained only by two examiners. Each case was examined by a single examiner, also reducing variability in the measurements. 


\section{Conclusions}

MCA PI reduces immediately after onset of fetal movements and/or fetal breathing in both AGA and SGA fetuses. This fall in MCA PI was below the $5^{\text {th }}$ centile in a significant proportion.

All AGA fetuses had episodes of MCA PI falling below the $5^{\text {th }}$ percentile. MCA PI started rising immediately after cessation of body movements and/or breathing movements in both AGA and SGA fetuses. A repeat measurement after a period of up to 90 seconds will allow the MCA PI to recover in $95 \%$ of fetuses. Repeat measurement should be taken after a period of up to 90 seconds after cessation of fetal body and/or breathing movements. This will minimize false positive diagnosis of cerebral sparing effect.

\section{Author's Contribution}

Anirudh Badade: Project development, Data Collection, Manuscript writing; Kalpesh Khatal: Data collection; Amarnath Bhide: Manuscript writing, Editing.

\section{Consent}

Informed consent was obtained from all individual participants included in the study.

\section{References}

[1] Vyas, S., Nicolaides, K.H., Bower, S. and Campbell, S. (1990) Middle Cerebral Artery Flow Velocity Waveforms in Fetal Hypoxaemia. British Journal of Obstetrics \& Gynaecology, 97, 797-803. https://doi.org/10.1111/j.1471-0528.1990.tb02573.x

[2] Hecher, K., Campbell, S., Doyle, P., Harrington, K. and Nicolaides, K. (1995) Assessment of Fetal Compromise by Doppler Ultrasound Investigation of the Fetal Circulation: Arterial, Intracardiac, and Venous Blood Flow Velocity Studies. Circulation, 91, 129-138. https://doi.org/10.1161/01.CIR.91.1.129

[3] Ebbing, C., Rasmussen, S. and Kiserud, T. (2007) Middle Cerebral Artery Blood Flow Velocities and Pulsatility Index and the Cerebroplacental Pulsatility Ratio: Longitudinal Reference Ranges and Terms for Serial Measurements. Ultrasound in Obstetrics \& Gynecology, 30, 287-296. https://doi.org/10.1002/uog.4088

[4] Bamfo, J.E.A.K. and Odibo, A.O. (2011) Diagnosis and Management of Fetal Growth Restriction. Journal of Pregnancy, 2011, Article ID: 640715.

[5] (2013) The Investigation and Management of the Small-for-Gestational-Age Fetus. Green-Top Guideline No. 31. 2nd Edition, Minor Revisions-January 2014.

[6] Fong, K.W., Ohlsson, A., Hannah, M.E., Grisaru, S., Kingdom, J., Cohen, H., Ryan, M., Windrim, R., Foster, G. and Amankwah, K. (1999) Prediction of Perinatal Outcome in Fetuses Suspected to Have Intrauterine Growth Restriction: Doppler study of Fetal Cerebral, Renal, and Umbilical Arteries. Radiology, 213, 681-689. https://doi.org/10.1148/radiology.213.3.r99dc08681

[7] Arduini, D. and Rizzo, G. (1992) Prediction of Fetal Outcome in Small for Gestational Age Fetus: Comparison of Doppler Measurements Obtained from Different Fetal Vessels. Journal of Perinatal Medicine, 20, 29-38.

https://doi.org/10.1515/jpme.1992.20.1.29 
[8] Clerici, G., Luzietti, R., Cutuli, A. and Direnzo, G.C. (2002) Cerebral Hemodynamics and Fetal Behavioral States. Ultrasound in Obstetrics \& Gynecology, 19, 340-343. https://doi.org/10.1046/j.1469-0705.2002.00634.x

[9] Richardson, B.S. (1992) The Effect of Behavioural State on Fetal Metabolism and Blood Flow Circulation. Seminars in Perinatology, 16, 227-233.

[10] Bhide, A., Acharya, G., Bilardo, C.M., Brezinka, C., Cafici, D., Hernandez Andrade, E., Kalache, K., Kingdom, J., Kiserud, T., Lee, W., Lees, C., Leung, K.Y., Malinger, G., Mari, G., Prefumo, F., Sepulveda, W. and Trudinger, B. (2013) ISUOG Practice Guidelines: Use of Doppler Ultrasonography in Obstetrics. Ultrasound in Obstetrics \& Gynecology, 41, 233-239.

[11] Badade, A.B., Bhide, A., Satoskar, P. and Wadekar, D. (2013) Validation of the Global Reference for Fetal Weight and Birth Weight Percentiles. Indian Journal of Radiology and Imaging, 23, 266-268. https://doi.org/10.4103/0971-3026.120270

[12] Marsal, K., Lindblad, A., Lingman, G. and Eik-Nes, S. (1984) Blood Flow in the Descending Aorta: Intrinsic Factors Affecting Fetal Blood Flow i.e. Fetal Breathing Movements and Cardiac Arrhythmias. Ultrasound in Medicine \& Biology, 10, 339-348. https://doi.org/10.1016/0301-5629(84)90168-6

[13] Sahoo, R., Nayak, S., et al. (2015) Doppler Assessment of the Fetus with Intrauterine Growth Restriction. International Journal of Pharmaceutical Sciences Review and Research, 32, 162-170. 